\title{
School Mental Health Programme for Teachers Recruited Through Corporate Social Responsibility : A Quasi Experimental Study
}

\author{
Vidya Naik ${ }^{1}$ \\ Nithyananda $S^{2}$ \\ Chaithra Chandrakanth ${ }^{3}$ \\ Virupaksha H.G. ${ }^{4}$ \\ Reshma B.K. ${ }^{5}$ \\ Shrinivasa Basavaraj ${ }^{6}$ \\ Julian A. Joseph Arthur \\ Anekal C. Amaresha ${ }^{8}$ \\ 1,2,5 M. Phil Scholar \\ ${ }^{3}$ Psychiatric Social Worker \\ $4,6,7,8$ Ph.D. Scholar \\ Department of Psychiatric Social Work, National Institute of Mental Health and Neurosciences \\ (NIMHANS), Bangalore. \\ E-mail -arthurjoseph7@gmail.com
}

\begin{abstract}
School Mental Health Programmes (SMHP), are being conducted
\end{abstract} for school teachers in Bangalore. Corporate Social Responsibility (CSR) is playing a pivotal role in providing educational services. However teachers in these programmes are not adequately trained to identify the mental health issues related to children. The aim was to study the usefulness of a brief SMHP for school teachers working as part of a CSR project in Bangalore. Twenty two school teachers of a CSR project participated in a brief SMHP. The program aimed at orienting the teachers' in common mental issues of children. Data was collected using a semi structured self reported interview schedule before and after the intervention which included 5 domains such as developmental, learning, behavioural, anxiety and severe mental disorders. The median age of the respondents was 26 years. Majority of them were females $(N=18)$, unmarried $(N=14)$, of an urban background $(N=15)$ of Bangalore. There was a significant improvement in post assessment scores on all the domains compared to baseline indicating the improved knowledge of the teachers. Participants in this SMHP gained increased knowledge on children's mental health issues and managing them at school level. However, further systematic studies with larger sample are required to generalize the findings.

Keywords: School Mental Health, Teachers, and Corporate Social Responsibility. 


\section{INTRODUCTION}

In India the number of children in the last decade has doubled. Children of today are considered to be the future of our tomorrow. However they are vulnerable to many problems especially mental health disorders that can affect their entire childhood - a period in which learning and socialization occurs in school, a place where they spend most of their time [1] which is considered to be important for their holistic growth and development. Childhood mental disorders significantly affect the academic achievement and social functioning of school attending children [2-3]. According to the recent systematic review and meta-analysis the prevalence of child and adolescent psychiatric disorders is found to be $6.5 \%$ in the community and it is $23.3 \%$ among school children [4]. With the growing number of children a genuine concern of the hour is the number of available staff who would be able to identify and address the child's mental health needs, as this has often been overlooked and not incorporated in the curriculum of the teachers [5].

Research shows that teachers' have limited knowledge or training in identifying, understanding and managing child and adolescent mental disorders [6-7]. Several studies have highlighted that teachers and other personnel in the schools require school mental health programs to help children with special mental health needs [8-9]. School serves as an important place to the children as that's where the holistic development takes place, which is important and cost effective as well [10]. It can also act as a guide to identify children who are at risk for mental disorders and can reduce the stigma among the students and teachers [10].

Corporate Social Responsibility (CSR) is involved in the education sector and provides more advanced infrastructure (i.e. manpower and innovative teaching and training methods with the advent technologies) which helps in improving the quality of education in India by supporting regular public and private schools [11]. However, school teachers often have difficulties in managing their work life balance [12-13]. Therefore making it ideal to orient or train them especially with those who are closely working with the children in schools. Many studies have explored providing school mental health programs to teachers and school children. However there is dearth of studies when it comes to providing school mental health orientation to the teaching staff working in educational programs under CSR projects.

In general there is a lack of mental health care professionals in India as a result it is almost impractical to have professionally trained social workers to address the mental health concerns of children in schools. In such cases it calls for decentralization of services and integration with the available resources in the community. Programmes designed to train teachers in assessing and identification of mental health concerns are in the need of the hour. Therefore in order to address this gap in the literature the aim of the current study was to assess the usefulness of a brief SMHP for school teachers working as a part of a CSR project in Bangalore.

\section{METHODOLOGY}

\section{Participants and Setting}

Life Trust Bangalore is a CSR initiative primarily aiming to improve the quality of education in municipal schools by capacity building programs and infrastructure 
development. We have invited thirty formal and informal school teachers to participate in the SMHP. These teachers were employed in one of the CSR project implemented in Bangalore which is working with government and private schools in the outskirts of Bangalore. They teach a formal curriculum as well as other extra-curricular activities to the children aged between 5 to 15 years. Finally 22 teachers consented and underwent the program. The study was conducted in the month of October 2014 and written informed consent was obtained from all the participants.

\section{Brief School Mental health Program}

The program had five sessions consisting of developmental disorders, learning disabilities, behavioral disorders, emotional disorders and severe mental illness related to child and adolescents. The content and methodology for SMHP was designed after several discussions among the research team. The content of the each session included was introduction to the particular group of disorders, various types and their characteristics, management and the role of school teachers in helping children with these disorders. The duration of the each session was ranged from 45 to $60 \mathrm{~min}$. At the end of the each session participants were given the opportunity to clarify their doubts regarding the session. The sessions were delivered through a mixture of methods including didactic lectures and interactive sessions with audio visual aids to make it easy for comprehension. The sessions were explained in participants' vernacular language Kannada.

\section{Interviews and Data Collection}

A semi-structured interview schedule was prepared consisting of socio demographic details and 40 questions on five broad domains (developmental disorders, learning disorders, behavioral disorders, emotional disorders, severe mental illness) to test the participants knowledge about child and adolescent mental disorders, characteristics, types and management etc. Participants were given the options such as "adequate=2, inadequate $=1$ and $\mathrm{Nil}=0$ " to chose to answer for each of the questions. Data was collected at baseline (prior to the program) and immediately after completion of the programme. The research team clearly instructed and assisted each participant to give their own answers for each question. In case of any missing data the participants were contacted to complete the form on the same day of the program.

\section{Data Analysis}

R Software (version 3.1.2) was used for statistical analysis. The socio-demographic data was presented with frequencies, percentiles, mean and median. Since the sample size was very small, non-parametric statistical test such as Wilcoxon signed rank test was administered to see the differences in teacher's knowledge about the mental health issues related to the child and adolescents at baseline and soon after the completion of the brief SMHP.

\section{RESULTS}

The socio demographic results (See Table. 1 ) showed that median age of the participants was 26 years; majority were female $(n=18)$; median years of education was 15; majority were unmarried $(n=14)$; belonging to Hindu religion $(n=20)$; 
hailing from an urban background $(n=15)$; and earning a monthly amount of Rs. 8000 . Most of the teachers were placed in government schools $(n=18)$; working in an urban area $(n=20)$ and teaching middle school children $(n=14)$. The median years of work experience was 2 years; most of them did not study mental health aspects of children in their degree or college $(n=14)$ nor did they attend any training program related to the same $(n=21)$. Majority of the participants reported that they did not come across children with mental health issues $(n=12)$.

Table 1 - Socio Demographic Details of the Participants

\begin{tabular}{|c|c|c|}
\hline Age & Median $=26$ & $* 27.36 \pm 6.09$ \\
\hline \multirow[t]{2}{*}{ Gender } & Male & $4(18.2)$ \\
\hline & Female & $18(81.8)$ \\
\hline Years of Education & Median $=15$ & $* 15.45 \pm 1.73$ \\
\hline \multirow[t]{2}{*}{ Marital } & Single & $14(63.6)$ \\
\hline & Married & $8(36.4)$ \\
\hline \multirow[t]{2}{*}{ Domicile } & Urban & $15(68.2)$ \\
\hline & Rural & $7(31.8)$ \\
\hline Monthly Salary & Median $=8000$ & $* 7500 \pm 1164.96$ \\
\hline \multirow[t]{2}{*}{ School } & Government & $18(81.8)$ \\
\hline & Private & $4(18.2)$ \\
\hline \multirow[t]{2}{*}{ Workplace } & Urban & $20(90.9)$ \\
\hline & Rural & $2(9.1)$ \\
\hline \multirow[t]{4}{*}{ Class of teaching } & Middle & $14(63.6)$ \\
\hline & High School & $6(27.3)$ \\
\hline & Primary \& Middle School & $1(4.5)$ \\
\hline & All of the Above & $1(4.5)$ \\
\hline Experience in teaching & Median=2years & $* 2.22 \pm 2.20$ \\
\hline \multirow{2}{*}{$\begin{array}{l}\text { Did you study Children's Mental Health } \\
\text { aspects in your college/degree? }\end{array}$} & Yes & $8(36.4)$ \\
\hline & No & $14(63.6)$ \\
\hline \multirow{2}{*}{$\begin{array}{l}\text { Did you attend any training program on } \\
\text { school mental health program? }\end{array}$} & Yes & $1(4.5)$ \\
\hline & No & $21(95.5)$ \\
\hline \multirow{2}{*}{$\begin{array}{l}\text { Did you come across any child with } \\
\text { mental health problem? }\end{array}$} & Yes & $12(54.5)$ \\
\hline & No & $10(45.5)$ \\
\hline
\end{tabular}

* Mean \pm SD

The Wilcoxon sign rank test (see Table.2) revealed that there was a significant difference at post SMHP in the total score of the participant's knowledge compared to the baseline $(z=4.01 ; p<0.001)$. There was an increase of the knowledge which was slightly higher in domains such as developmental $(z=4.02 ; p<0.001)$, behavioral $(z=4.02 ; p<0.001)$ and severe mental disorders $(z=4.02 ; p<0.001)$ as that of learning $(z=3.63 ; p<0.001)$ and emotional disorders $(z=3.92 ; p<0.001)$. 
Table2 - Comparison of Teachers Knowledge on Children's Mental Health Issues

\begin{tabular}{|l|l|l|l|l|}
\hline Domains & Baseline & Post Assessment & z & p \\
\cline { 2 - 4 } & Mean \pm SD & Mean \pm SD & & \\
\hline $\begin{array}{l}\text { Developmental } \\
\text { Disorder }\end{array}$ & $7.36 \pm 4.22$ & $17.77 \pm 3.75$ & 4.02 & $<0.001$ \\
\hline Learning Disabilities & $5.77 \pm 2.77$ & $8.72 \pm 1.72$ & 3.63 & $<0.001$ \\
\hline Behavioural Disorders & $6.22 \pm 4.94$ & $13.18 \pm 2.71$ & 4.02 & $<0.001$ \\
\hline Emotional Disorders & $7.68 \pm 4.50$ & $15.50 \pm 2.90$ & 3.92 & $<0.001$ \\
\hline $\begin{array}{l}\text { Severe mental } \\
\text { Disorders }\end{array}$ & $2.95 \pm 3.75$ & $12.77 \pm 3.44$ & 4.02 & $<0.001$ \\
\hline Total Scores & $30.0 \pm 18.01$ & $67.95 \pm 11.83$ & 4.01 & $<0.001$ \\
\hline
\end{tabular}

\section{DISCUSSION}

The findings of the current study showed that the participant's knowledge about child and adolescent mental disorders has significantly increased after attending the brief SMHP. Though their knowledge in all the domains have improved, domains such as developmental disorders, behavioural disorders and severe mental disorders were higher than others. Though there is dearth of SMHP studies concerning teachers working in CSR and other community programs or projects, there are several studies that have been carried out with formal school teachers in India [14-16]. The current findings are in tune with these previous studies where they have found that SMHP had improved the school teacher's knowledge on child and adolescent mental disorders [14-16].

The knowledge gained by the teachers have to be viewed in the light of the "principles of rapid knowledge improvement", where the voluntary, democratized participation and use of audio-visual aids influences the rapid knowledge gain [17]. The teacher training curriculum in India contains concepts such as child and adolescent learning and emotional health of the children. However, it does not emphasize on the child and adolescents mental disorders [5]. The teachers prior understanding on learning behaviours and emotional health of the children might have potentially contributed to their level of new knowledge gain about the learning and emotional disorders. The lack of emphasis on other disorders in the curriculum or training would have influenced the significant increase in mental health knowledge in developmental, behavioural and severe mental disorders.

Though the results have generated significant findings, the study has its share of limitations and one should take caution to generalize the findings. The small sample size selected from an urban CSR project, predominantly female teachers, with the absence of a waitlist or control group and the post assessment being conducted soon after the programme are some of the limitations. The lack of standardized tools for the assessment of teacher's knowledge could have generated more reliable results. Though the study has these limitations it has certain strengths as well. Firstly, to the best of our knowledge this is the first brief SMHP program conducted with teachers of CSR project by professional Psychiatric Social Workers. Secondly, the use of audio-visual aids while delivering the sessions and obtaining subjective responses to the semi- 
structured questionnaire on knowledge were some of the other strengths. Finally, the qualitative study conducted as part of this program, which is published elsewhere [18] found that the participant's felt the program as useful in enriching their knowledge. They were receptive and expressed their need for series of programs on each disorder for comprehensive understanding [18].

\section{Implications to Social Work Education, Practice and Research}

- Social Work Curriculum and Training: The social work curriculum can include school mental health aspects to orient the social work trainees on this topic. It will be beneficial to conduct workshops and provide hands on experience in training the social work students in identifying child and adolescents with mental health disorders and providing social work interventions at schools. Social work trainees can be supervised to organize and conduct School Mental Health Programs to expose them in addressing the issues of child and adolescent mental disorders. This will also help in addressing the issue of lack of manpower to an extent.

- Capacity building programs for community based organizations/NGOs: Tertiary care psychiatric settings giving expertise and training in SMHP to the NGO personnel would be helpful to reach the schools in the community and unreached areas.

- Orientation to the Corporate Sector: CSR projects invest a large amount of money in the education sector. However mental health aspects of children in their educational initiative have not been given much importance. In this context the corporate companies need to be oriented on child and adolescent psychiatric disorders in a larger perspective to emphasize on the mental health needs of children and provide support to the teachers in acquiring child mental health literacy.

- Systematic Research: The current literature shows that further systematic research is needed in terms of large scale randomized prospective controlled trials with blind ratings in order to address the lacunae in the existing research.

The Brief SMHP was found to be useful with teachers working in the CSR projects as it improved the knowledge in all the domains of child and adolescent mental disorders. However, this study warrants further research to generalize the findings.

\section{REFERENCES}

1. Slade EP. Effects of school-based mental health programs on mental health service use by adolescents at school and in the community. Ment Health Serv Res 2002;4(3):15166.

2. Myer L, Stein DJ, Jackson PB, Herman AA, Seedat S, Williams DR. Impact of common mental disorders during childhood and adolescence on secondary school completion. SAMJ: South Afr Med J 2009;99(5):354-6.

3. Tempelaar WM, Otjes CP, Bun CJ, Plevier CM, van Gastel WA, MacCabe JH, et al. Delayed school progression and mental health problems in adolescence: a populationbased study in 10,803 adolescents. BMC Psychiatry 2014;14:244.

4. Malhotra S, Patra BN. Prevalence of child and adolescent psychiatric disorders in India: a systematic review and meta-analysis. Child Adolesc Psychiatry Ment Health 2014;8:22-8.

5. NCTE. National Curriculum Framework for Teacher Education. New Delhi: NCTE2009. 
6. Ghanizadeh A, Bahredar MJ, Moeini SR. Knowledge and attitudes towards attention deficit hyperactivity disorder among elementary school teachers. Patient Educn Couns 2006;63(1-2):84-8.

7. Walter HJ, Gouze K, Lim KG. Teachers' beliefs about mental health needs in inner city elementary schools. J Am Acad Child Adolesc Psychiatry 2006;45(1):61-8.

8. Kutcher S, Wei Y, McLuckie A, Bullock L. Educator mental health literacy: a programme evaluation of the teacher training education on the mental health \& high school curriculum guide. Adv School Ment Health Prom 2013;6(2):83-93.

9. Mansour ME, Kotagal UP, DeWitt TG, Rose B, Sherman SN. Urban elementary school personnel's perceptions of student health and student health needs. Ambulatory Pediatr 2002;2(2):127-31.

10. Kutcher S, Venn D, Szumilas M. Mental Health: The next frontier of health education. Education Canada 2009;49(2):45-50.

11. Chopra A, Marriya S. Corporate Social Responsibility and Education in India. Issues and Ideas in Education 2013;1:13-22.

12. Hakanen JJ, Bakker AB, Schaufeli WB. Burnout and work engagement among teachers. J School Psychol 2006;43(6):495-513.

13. Mondal J, Shrestha S, Bhaila A. School teachers: Job stress and job satisfaction, Kaski, Nepal. Int J Occupat Safety Health 2011;1(1):27-33.

14. Daniel LT, Gupta S, Sagar R. Effect of Educational Module on Knowledge of Primary School Teachers Regarding Early Symptoms of Childhood Psychiatric Disorders. Ind J Psychol Med 2013;35(4):368-72.

15. Kumar D, Dubey I, Bhattacharjee D, Singh NK, Dotiwala KN, Siddiqui SV. Beginning Steps in School Mental Health in India: A Teacher Workshop. Adv School Ment Health Prom 2009;2(4):28-33.

16. Shah $H$, Kumar D. Sensitizing the teachers towards school mental health issues: an Indian experience. Comm Ment Health J 2012;48(4):522-6.

17. Looi CK, Patton C, Chen W. Rapid Collaborative Knowledge Improvement. In: Seel N, editor. Encyclopedia of the Sciences of Learning: Springer US; 2012. p. 2759-62.

18. Shrinivasa B, Reshma BK, Virupaksha HG, Chaithra C, Vidya N, Nithyananda S, et al. Experiences of School Teachers on Participation in a Brief School Mental Health Program: A Qualitative Inquiry. Advances in School Mental Health Promotion. 2015. Epub Nov 2015 (Article in Press).

Acknowledgements - We acknowledge the support of Mr. Anand (Coordinator of Life Trust, Bangalore) in conducting this School Mental Health Programme. We would also like to thank the participants.

Conflict of Interest - Nil

Funding - Nil. 